\title{
Adolescent Exposure of JWH-018 “Spice” Produces Subtle Effects on Learning and Memory Performance in Adulthood
}

\author{
David M. Compton, Megan Seeds, Grant Pottash, Brian Gradwohl, Chris Welton, Ross Davids \\ Department of Psychology, Donnelley Behavioral Neuroscience Laboratory, Palm Beach Atlantic University, \\ West Palm Beach, USA \\ Email: David_Compton@pba.edu
}

Received November 11, 2011; revised January 19, 2012; accepted February 22, 2012

\begin{abstract}
The active components associated with the bio-designer drugs known variously as "Spice" or "K2" have rapidly gained in popularity among recreational users, forcing the United States Drug Enforcement Administration to classify these compounds as Schedule I drugs in the Spring of 2011. However, although there is some information about many of the synthetic cannabinoids used in Spice products, little is known about the consequences of the main constituent, (1-pentyl-3-(1-naphthoyl)indole; JWH-018), on neuropsychological development or behavior. In the present experiment, adolescent rats were given repeated injections of either saline or $100 \mu \mathrm{g} / \mathrm{kg}$ of JWH- 018 . Once the animals were 75 days of age, they were trained using tasks with spatial components of various levels of difficulty and a spatial learning set task. On early trials with water maze tasks of varying difficulty, the JWH-018 treated rats were impaired relative to controls. However, by the end of each phase of testing, drug and control animals were comparable, although on probe trials the drug-treated animals spent significantly less time in the target quadrant. In addition, the performance of the drug-treated rats was inferior to that of the control animals on a learning set task, suggesting some difficulty in adapting their responses to changing task demands. The results suggest that chronic exposure to this potent cannabinoid CB1 receptor agonist during adolescence is capable of producing a variety of subtle changes affecting spatial learning and memory performance in adulthood, well after the drug exposure period.
\end{abstract}

Keywords: 1-Pentyl-3-(1-naphthoyl)indole; JWH-018; K2; Spice; Spatial Learning; Morris Water Maze; Development; Memory

\section{Introduction}

Because of their effects on the mind, cannabinoids have been used recreationally by humans for over 4000 years [1]. Cannabinoid use has been associated with a variety of neuropsychological effects including diminished motor coordination, a disruption of short-term memory, and a reduction in the ability to maintain attentional focus [2-4]. In addition, exposure to cannabinoids also produces a number of cognitive effects $[5,6]$.

Two cannabinoid receptors, CB1 receptor CB2, have been identified. However, until recently the accumulated evidence (see [6]) suggested that the CB1 receptor acts within the central nervous system (CNS) while the CB2 is associated with the immune system and not expressed in the CNS [7,8]. Two endogenous compounds, anandamide and 2-arachidonylglycerol, have been identified so far with both acting as CB1 agonists [9]. The CB1 receptors in the CNS endocannabinoid system are presynaptic [1] and are considered neuroregulatory influencing other neurontransmitter systems including glutamate, GABA, and dopamine [8].

As noted above, cannabinoid use is associated with disturbances in cognition and perturbations in psychomotor task performance $[5,6,8,10,11]$. Further, some of the reported effects appear to last for a considerable period following drug exposure [12]. In rats, the timing of the exposure during the neurophysiological development of the organism appears to contribute to impairments in working memory when tested as adults while adult $\Delta-9$ THC-treated rats does not produce persistent impairments $[13,14]$. Last, such adolescent exposure effects may, in part, be associated with the sex of the animal as well, with more severe effects reported in female rats [15].

The terms "K2" or "Spice" typically refer to a group of products sold for a variety of purposes from herbal incense to bonsai fertilizer [16]. While these compounds were marketed for nonhuman use, in actuality they were viewed as legal alternatives to marijuana and were usu- 
ally purchased for the purpose of intoxication [17]. Spice products contain a variety of synthetic cannabinoids and have gained popularity among recreational drug users since the middle of the previous decade [18-20]. However, as of March, 2011, the US Drug Enforcement Administration (DEA) published a final order in the Federal Register temporarily placing the five most popular synthetic cannabinoids into Schedule I of the Controlled Substances Act, thus making sale or possession illegal [21]. Nonetheless, coupled with their former legal status and the fact that the typical urine drugs-of-abuse screening procedures were ineffective [22] their popularity has continued [23].

Little is known about the toxicology of 1-pentyl-3-(1naphthoyl)indole (JWH-018) and the related compounds reported used in Spice products. However, there is some evidence that these synthetic cannabinoids cause both dependence and withdrawal [24]. Like many of the Spice compounds, JWH-018 strongly binds with CB1 receptors, acting as a receptor agonist and influencing a number signaling pathways [25]. According to Vardakou et al. [17], the subjective effects associated with ingestion of Spice products are the result of JWH- 018 and sister compounds action on CB1 receptors (see also $[25,26])$. As the number of users has increased, so have reports concerning the side effects. For example, earlier in the past decade the American Association of Poison Control Centers reported a total of 13 calls related to the use of synthetic cannabinoids and Spice products. However, by 2010 the number of calls exceeded 3000 [27] while in Sweden there has been a marked increase in the number of cases of what has come to be known as "Spice toxicity" [28].

There are reports that chronic cannabinoid use has no long-term consequences following a period of abstinence and recovery $[29,30]$. However, as is the case with a number of drugs of abuse, the exposure period within the lifespan of organism may be a critical variable. For example, Stiglick and Kalant [31] reported that immature rats were more severely affected than adult rats with a comparable level of THC exposure. This appears to be true of synthetic cannabinoids that act as CB1 agonists as well. Rats exposed to WIN 55212-2 during adolescence postnatal day (PND) 40 to 65 were impaired on a number of tasks and emotional measures $[14,32,33]$ while WIN 55212-2treated adult rats were not impaired [14,33]. In another investigation, rats exposed to WIN 55212-2 were not impaired on locomotor or recognition memory measures but had a number of anxiety-related behavioral disturbances as adults [32]. This is consistent with other reports about the anxiogenic effects of CB1 agonists such as HU-210 [9,34], a compound also used in Spice preparations [20]. Last, CP 55940 exposure during adolescence produced a number of behavioral effects when measured in adulthood, with sex differences also observed
[35]. Working memory deficits after adolescent exposure have also been found [15]. To reiterate, the timing of the drug exposure may very well produce different but long-lasting effects.

Adolescence is defined in rats as a period lasting from the 21st PND following birth until PND 60 [36]. Within this period of development, mid adolescence includes PND 34 to 46 and late adolescence is defined as from PND 46 to 59. These two periods can be considered as analogous to periadolescence and late adolescence/early adulthood, respectively [36]. The use of a rodent model to understand neurodevelopmental changes is useful for both comparative evaluations and for extrapolation to humans [37]. Thus, the use of adolescent animals can provide a valuable experimental framework for examining the developmental consequences associated with drugs of abuse at various points in biological and cognitive development.

Unfortunately, with the exception of anecdotal descriptions reported on the internet (see e.g., [38]) forensic or toxicological reports [22], anecdotes or examination of trends of use [39-42], and toxicological investigations [17,23,43] there is little published information on the effects of many of these compounds, especially JWH-018, on the central nervous system. While acknowledging the possibility that these compounds may have therapeutic uses [41], given the growing popularity of the Spice compounds, the possible risks on development in vulnerable adolescents could become a major concern, especially as a potential societal health problem. Further, there are no published studies on the long-term effects of developmental exposure to the Spice compounds on the physiology of learning, and memory. Understanding such effects may be important because as the use of the synthetic cannabinoids generally increases so too, will the consequences.

Therefore, the present study was conducted as a first step to examine the influence of the potent synthetic CB1 agonist JWH-018 [25] on learning and memory performance in Morris water maze (MWM) tasks of varying difficulty. Specifically, the animals were trained on a cued version of the MWM to evaluate whether nonassociative factors (e.g., sensorimotor/swimming deficits) affected place learning performance. A series of non-cued MWM tasks of varying difficulty were used to evaluate learning, memory, and via probe trials, retention. Finally, a simple response set learning task was employed to explore possible response perseveration and memory deficits.

\section{Materials and Methods}

\subsection{Subjects and Drug Administration}

\subsubsection{Subjects}

The subjects consisted of 17 male experimentally naive Long-Evans rats (Charles River, Wilmington, MA). The 
research protocol was reviewed and approved by the Institutional Animal Care and Use Committee of Palm Beach Atlantic University. The animals were cared for in a manner consistent with the principles of animal care outlined in the Guide for the Care and Use of Laboratory Animals [44]. Drug exposure began when the rats were in the mid-adolescent period of development (i.e., 35 days old). All animals received a total of six injections, with each injection spaced 48 hours apart. Thus, the rats were exposed to either JWH-018 $(n=8)$ or saline $(n=9)$ from 35 to 45 days of age. The rats were individually housed in stainless steel suspended cages and maintained on a 12-hr light/12-hr dark cycle with the lights on at 7:00 am. Throughout the experiment, the animals were provided with ad lib access to water and food (Mazuri Rodent Chow).

\subsubsection{Drug Administration}

JWH-018 (Tocris Bioscience, Ellisville, MO) was dissolved in solution consisting of an ethanol:emulphor:physiological saline at a ratio of $1: 1: 18$. The animals in the control groups received the respective vehicle with all injections given i.p. A dose of $100 \mu \mathrm{g} / \mathrm{kg}$ was used after pilot testing with rats not included in the present study using $50 \mu \mathrm{g} / \mathrm{kg}, 100 \mu \mathrm{g} / \mathrm{kg}$, and $250 \mu \mathrm{g} / \mathrm{kg}$ doses and an assessment that included examining the behavioral effects.

\subsection{Assessment of Nonmemory-Related Deficits}

\subsubsection{Activity Assessment}

General locomotor activity levels were evaluated for 5 minutes in a $24 \times 24$ chamber consisting of 6 squares (i.e., a checkerboard). General measures of activity were determined by the number of squares crossed during the measurement period. The number of rearings was also recorded.

\subsubsection{Sensorimotor Assessment-Rotating Rod Test}

In the rotating rod test, a motor rotated a wooden dowel (10 cm in circumference \& $162 \mathrm{~cm}$ long) at a speed of 5 rotations per minute. The dowel will be wrapped with tape to help prevent the rat from slipping and elevated $100 \mathrm{~cm}$ above the floor. Approximately $15 \mathrm{~cm}$ of foam padding was placed beneath the apparatus to prevent injury in case a rat fell.

One minute before the beginning of each assessment, the motor was turned on in order to acclimate the rat to the sound. An assessment began when the rat was placed onto the rod and the experimenter verified placement of all four feet. The experimenter counted the number of slips and falls for a one minute period. Slips were scored whenever the rat fell off the rod but still held onto the rod through one rotation. Falls were scored whenever the rat fell off of the rod. When a rat slipped or fell, it was immediately repositioned on the rod.

\subsection{Water Maze Navigation Tasks}

In addition to tests of spatial learning and learning set performance, the water maze protocol employed in the present experiment was used to evaluate the possibilities that nonassociative factors such as motivational changes or sensorimotor disturbances might impact swimming performance. By changing the parameters of the place procedures to make the task more or less challenging, we hoped that the procedures would be sensitive to non-memory impairments should they exist.

With the exception of general activity, all behavioral testing occurred in a circular swimming pool $183 \mathrm{~cm}$ in diameter and composed of a white acrylic plastic. Water was filled to a depth of $30 \mathrm{~cm}$ and made opaque by the addition of nontoxic white paint (Sargant Art, Hazelton, PA). The pool was located in a testing room approximately 36.88 square meters in size. An escape platform painted flat white and $15 \mathrm{~cm} \times 15 \mathrm{~cm}$ in diameter was located $18 \mathrm{~cm}$ from the wall of the swimming pool. For the cued water maze task, the platform protruded $15 \mathrm{~mm}$ above the surface of the water. For all remaining water maze phases the platform was submerged $15 \mathrm{~mm}$ below the surface of the water. With the exception of the probe trials, across all phases of training on each trial the rat was released into the pool at one of four release points, north, south, east, or west, and permitted to locate the platform. Platform location varied at one of four positions - northeast, northwest, southeast, or southwest. All trials were given a ceiling of 60 seconds, at which point the rat was placed on the platform. Swim times were recorded with a stopwatch and errors, defined as crossing one of four quadrants associated with the four compass points, were recorded.

In order to allow for direct comparison of swim latencies across start locations with different optimal swim path distances, the recorded escape latencies for of the four start locations were normalized. Normalization was accomplished by computation of the ratio of the minimum swim distance in centimeters for each of the two longer swim paths to the escape platform (e.g., north start location and a southwest goal location) to the minimum swim of the two shorter swim paths (e.g., north start location and a northwest goal location) trials in centimeters.

\subsubsection{Cued Place Learning Task}

Using a visible platform, the cued water maze task was included to assess sensorimotor (e.g., swimming ability, vision) and motivational deficits as well as acclimate the animals to the various elements of the water maze. This 
was done to assess or reduce non-memory processes that could influence performance during the spatial place and learning set tasks. The rats were trained for 20 trials (2 blocks of 10 consecutive trials) during 2 days of testing where each trial involved a different platform location. Rats were allowed to remain on the platform for $15 \mathrm{sec}-$ onds after each trial. Training on the cued water maze navigation task began when the rats were 75 days old, 30 days after the last drug exposure.

\subsubsection{Place Learning Water Maze Tasks}

The place learning tasks consisted of spatial reference memory-based tasks [45]. The task involved learning the location of a submerged platform that remained the same across all trials within a given phase. Because previous research in our laboratory involving the behavioral effects of different psychoactive compounds often demonstrated minor deficits using the standard version of this MWM test, we used two testing protocols (labeled Simple \& Complex) to determine if the complex version was more sensitive for detecting spatial learning/memory impairments over the post drug exposure period.

\subsubsection{The Simple Place Learning Task}

This protocol involved 10 trials per day for 2 days. In order to facilitate spatial learning, a number of salient spatial cues were located around the room. The rats were allowed to remain on the platform for 20 seconds after each trial. After daily training, retention was evaluated with probe trials, consisting of a single daily 60 seconds free swim with the escape platform removed. The probe trials occurred no less than two hours after the last training trial for the day. The time spent swimming in the target quadrant and the number of crossings over the former platform location were quantified.

\subsubsection{The Complex Place Learning Task}

In this task, all rats were trained 4 consecutive trials per day for 5 days. To increase the difficulty of the water maze task, the available extra-maze cues were minimized and the room illuminated by a single 40 watt red light bulb, thus leaving few cues to aid navigation. After reaching or placement on the platform, the rats were allowed to remain there for 15 seconds after each trial. Similar to the simple version of the tasks, probe trials were administered after the completion of test days four and five.

\subsubsection{Learning-Set Acquisition Testing}

Learning Set acquisition testing requires the animals to learn a new location for the escape platform each day for 5 consecutive days. Testing begin on post-drug exposure day 39 and continued through day 49. All animals received 4 consecutive trials per day. The averaged performance on Trial 2 of each day was used as an index of working (short-term) memory because in the task the animal is required to recall its response on the immediately preceding trial. The rats were allowed to sit on the platform for 15 seconds at the completion of each trial.

\section{Results}

\subsection{Assessment of General Activity and Motor Ability}

An ANOVA was used to explore the possible effect of the drug on motor performance. No drug associated effects were suggested in terms of quadrant crossings or rearings $(p s>0.05)$.

When the rats were tested using the rotating rod, the rats improved across sessions but no drug effects were observed on either the number of slips or the number of falls.

\subsection{Spatial Learning and Testing}

\subsubsection{Cued Place Learning Task}

The learning ability of the rats during the initial phase of training was examined by analyzing the swim trials in blocks of five swims. Using the swim time to the escape platform as the dependent measure, the data were analyzed using a 1-Between (2-Drug groups), 1-Within (4 blocks of trials) analysis of variance (ANOVA). Swim times to the escape platform were comparable for both groups. Escape times decreased as a function of training for all animals, $F(3,45)=29.05, p<0.001$, partial $\eta^{2}=$ 0.659 , but the drug group $\mathrm{X}$ trials interaction was nonsignificant.

\subsubsection{The Simple Place Learning Task}

The relevant results associated with the simple version of the place learning task are presented in Figure 1. Analysis of the resulting data with a 2 (drug groups) $\times 2$ (days) $\times 4$ (blocks) ANOVA indicated a nonsignificant main effect of drug, $F(1,15)=3.37, p=0.086$, but significant main effects of days, $F(1,15)=28.54, p<0.001$, partial $\eta^{2}=0.655$, and blocks, $F(3,45)=18.60, p<0.001$, partial $\eta^{2}=0.554$, suggesting that changing swim times generally improved between the blocks of trials as well as between days. In addition, significant drug $\times$ days, $F(1$, $15)=5.04, p<0.05$, partial $\eta^{2}=0.252$, and drug $\times$ blocks, $F(3,45)=5.12, p<0.05$, partial $\eta^{2}=0.270$, interactions were found. The three-way interaction was non-significant. Further consideration of the two-way interactions revealed the following. Swim times were significantly higher for the JWH-018 rats than saline controls on day 1 but not on day 2. Similarly, JWH-018 rats were impaired on blocks one and two but not on blocks three and four.

When the probe trials were considered a JWH-018 mediated impairment was observed (see Figure 1, inset). Specifically, main effects of drug, $F(1,15)=20.53, p<$ 0.001 , partial $\eta^{2}=0.578$, and days, $F(1,15)=11.36, p<$ 
0.01 , partial $\eta^{2}=0.431$, were found and, as evidenced by the lack of a significant drug $\times$ days interaction, the difference between the groups remained.

\subsubsection{The Complex Place Learning Task}

For the assessment of the complex place learning data, the four daily trials were normalized and averaged and the navigation performance was assessed over a five-day period. The results are presented in Figure 2. Using a 1-Between, 1-Within ANOVA, the analysis revealed main effects of the drug treatment, $F(1,15)=7.11, p<$ 0.025 , partial $\eta^{2}=0.321$, and test days, $F(4,60)=10.65$, $p<0.001$, partial $\eta^{2}=0.415$, suggesting that group swim times differed and that the swim times generally decreased across the five-day test period. However, as can also be seen in Figure 2, the drug group $\times$ test days interaction was nonsignificant, $F(4,60)=1.05, p=0.39$.

When the probe trials were assessed, only the main effect of days was significant, $F(1,15)=26.81, p<0.001$,

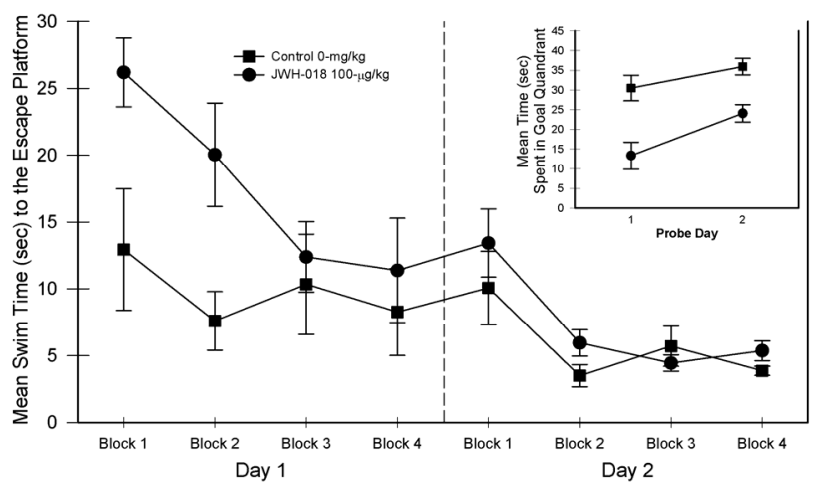

Figure 1. Simple (i.e., maximum extra-maze cues) place learning task performance in blocks of five trials for the two-day test period. Probe trial performance is presented as an inset in the graph. Vertical lines represent SEM.

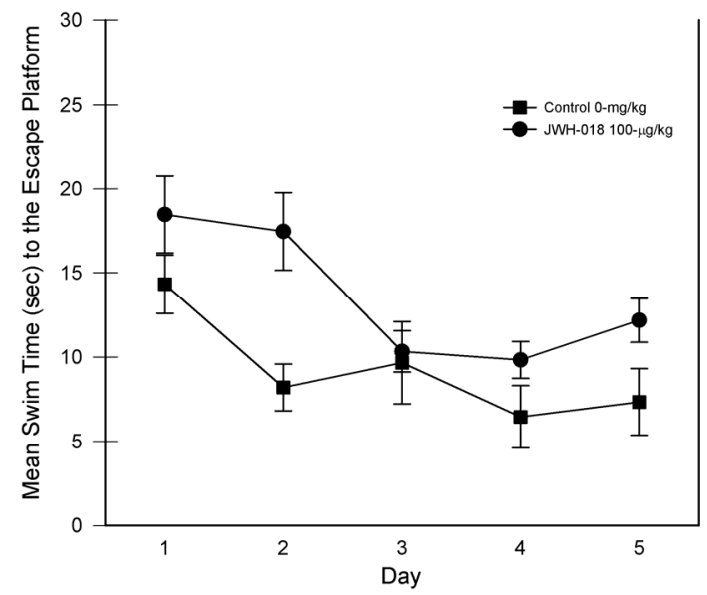

Figure 2. Complex (i.e., minimal extra-maze cues) place learning task performance for each of the five days of testing. Individual trials were collapsed for analysis. Vertical lines represent SEM. partial $\eta^{2}=0.641$, indicating that the rats spent more time in the target quadrant on later days but both groups responded in a similar manner.

\subsection{Learning Set Acquisition Testing}

The swim time data associated with the MWM learning set task is presented in Figure 3. Data involved averaging each trial from the five days of testing. Although the main effect of drug group was nonsignificant, the main effect of trials was significant, $F(3,45)=51.06, p<$ 0.001 , partial $\eta^{2}=0.773$. Thus, while across trials the swim times for the two groups were comparable, their performance improved with training. In addition, a drug group $\times$ trial interaction was detected, $F(3,45)=3.85, p$ $<0.05$, partial $\eta^{2}=0.204$, suggesting differential changes in swim times as a function of trial position. Focusing on trial one vs trial 2 performance in the decomposition of the interaction revealed significant reductions in swim times from trial one to trial two [smallest $F(1,7)=20.32$, $p<0.01$; see Figure 3, trials $1 \& 2$ )]. Although trial 1 of Figure 3 suggests a difference in swim times, post hoc comparison of the two groups revealed that the trial 1 swim times were not significantly different. Conversely, saline rats found the escape platform on trial 2 significantly faster than the JWH-018 treated rats. The swim time results are consistent with the number of quadrants crossed which was also higher in the drug-treated rats, $t(15)=-2.77, p<0.05$, partial $\eta^{2}=0.339$.

\section{Discussion}

Collectively, the cannabinoids include a number of compounds that act as agonists at endogenous cannabinoid receptors sites [8]. Included in this group are the compounds derived from the Cannabis sativa plant which

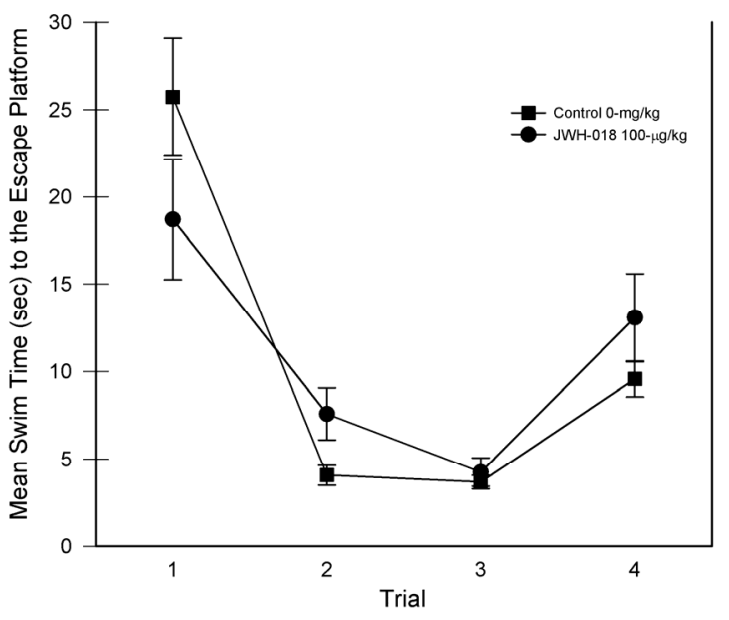

Figure 3. Learning set performance for each of the four daily trials. Daily performances were collapsed for analysis. Vertical lines represent SEM. 
includes $\triangle 9$-THC and $\triangle 8$-THC, endogenous cannabinoids such as Arachidonoylethanolamine (Anandamide) and 2-arachidonoyl glycerol (2-AG), and a number of synthetic cannabinoids [46]. The latter compounds were synthesized for research purposes at Hebrew University (HU compounds), Pfizer Pharmaceuticals, and a large group synthesized by J. W. Hoffman in the 1980s (labeled JWH compounds) [17].

Recently, a number of these synthetic cannabinoids have been detected in products labeled as Spice or K2 and include JWH-018, JWH-073, JWH-398, JWH-250 and HU-210. Although advertised as substances for nonhuman consumption [16], synthetic cannabinoids such as JWH-018 are mixed into a solvent and then sprayed on the plant [17] for delivery of what was formerly a legal high. In fact, JWH-018 was the first synthetic cannabinoid ever reported through the "Early Warning System" utilized in Europe to monitor emerging trends [23]. Since JWH-018 is a potent CB1 receptor agonist capable of activating multiple signaling pathways in the brain [47], the subjective effects of Spice are considered the result CB1 receptor activation by JWH-018 in Spice and K2 preparations [17].

Constituents of Cannabis sativa such as $\Delta 9-\mathrm{THC}$ are nonselective, binding with $\mathrm{CB} 1$ and $\mathrm{CB} 2$ receptors [47]. Until recently, the consensus was that the $\mathrm{CB} 1$ receptor was localized in the central nervous system and, thus responsible for the psychoactive effects of the cannabinoids. The CB2 receptor was considered a peripheral cell receptor class and was not associated with the well-documented psychoactive effects of cannabis [47,48]. Recently, as Sviženská et al. [1] noted, this view has begun to change following reports of $\mathrm{CB} 2$ receptors detected in microglia [49] and neurons [50]. Nonetheless, CB1 receptor numbers are particularly pronounced in areas of the brain normally associated with memory and cognition including areas of the hippocampus, dorsal striatum, amygdala, and a number of cortical regions including the prefrontal cortex [51-53]. The CB2 receptors have been identified as widely distributed throughout peripheral tissues with significant densities associated with immune tissues [1], with mixed results on the identification of CNS CB2 receptors (e.g., [49,54]).

In animal models, cognitive performance has been adversely impacted by cannabinoid agonists on a number of tasks $[6,55,56]$. For example, in learning tasks that are considered hippocampus-dependent, cannabinoid agonists normally produce an impairment, regardless of whether the task involves spatial reference memory [5760] or spatial working memory [11,61-63]. In such tasks, it is believed that the impairments are associated with activation of dorsal hippocampal CB1 receptors [64]. Further, in the eight-arm radial maze, impairments in memory retrieval are suggested by the fact that WIN $55212-2$ injections into the dorsal hippocampus produce an impairment in reference memory performance [63]. Consistent with this finding, post-training intrahippocampal injection of WIN 55212-2 disrupts long-term reference memory in the MWM, while sparing acquisition or short-term memory performance [65]. However, in one recent investigation evidence was reported that the CB1 agonist WIN 55212-2 produced deficits consistent with thigmotaxis rather than spatial learning per se [66].

While additional research will elucidate the cellular mechanisms involved in cannabinoid induced alterations in memory function [67], the available research suggests an association with critical reductions in glutamate. As a consequence, the cannabinoid-induced glutamate reductions impair activation of NMDA receptors involved in long-term potentiation and depression $[68,69]$. For example, in the hippocampus, CB1 receptors appear to influence release of both inhibitory and excitatory neurontransmitters, thus influencing synaptic plasticity [67]. Further, a variety of cannabinoid agonists including natural ligands such as THC and synthetic cannabinoids such as HU-210 and WIN 55212-2 disrupt spatial or operant hippocampus-dependent learning [68,70-73]. Conversely, cannabinoid antagonists such as SR141716A block the impairment in the induction of LTP $[72,73]$.

Of particular concern here is the possibility that adolescent exposure can lead to a number of disturbances in cognitive processes that persist long after abstinence. Consistent with this are reports of working memory impairments in adolescent but adult rats exposed to $\triangle 9-\mathrm{THC}$ when subsequently tested in adulthood $[13,14]$. However, the issue remains open for further inquiry as the residual effects associated with adolescent exposure are not always found [15].

In summary, the results reported here provide that adolescent exposure of at least one common psychoactive constituent of K2 (Spice) compounds, JWH-018, can produce alterations in learning and memory performance in adulthood. To repeat, during adolescence a number of areas of the brain are undergoing developmental changes with higher levels of novelty and sensation-seeking considered a common feature of adolescence [74]. Because presynaptic CB1 cannabinoid receptors have been discovered at serotoninergic, noradrenergic, glutamatergic, and GABAergic synapses in many areas of the brain [68,70-73,75-79] including those critical for accurate responses and memory processes [5], these abused synthetic cannabinoids should be examined in greater detail. Doing so may further define the specific consequences associated with adolescent use.

\section{Acknowledgements}

This work was partially supported by a Palm Beach Atlantic University Quality Initiative Grant awarded to the first author. 


\section{REFERENCES}

[1] I. Svíženská, P. Dubový and A. Šulcová, "Cannabinoid Receptors 1 and 2 (CB1 and CB2), Their Distribution, Ligands and Functional Involvement in Nervous System Structures-A Short Review," Pharmacology, Biochemistry and Behavior, Vol. 90, No. 4, 2008, pp. 501-511.

[2] R. I. Block, R. Farinpour and K. Braverman, "Acute Effects of Marijuana on Cognition: Relationships to Chronic Effects and Smoking Techniques," Pharmacology, Biochemistry and Behavior, Vol. 43, No. 3, 1992, pp. 907917. doi:10.1016/0091-3057(92)90424-E

[3] J. M. Court, "Cannabis and Brain Function," Journal of Paediatrics and Child Health, Vol. 34, No. 1, 1998, pp. 1-5. doi:10.1046/j.1440-1754.1998.00142.x

[4] S. J. Heishman, K. Arasteh and M. L. Stitzer, "Comparative Effects of Alcohol and Marijuana on Mood, Memory, and Performance," Pharmacology, Biochemistry and Behavior, Vol. 58, No. 1, 1997, pp. 93-101. doi:10.1016/S0091-3057(96)00456-X

[5] T. Pattij, J. Wiskerke and A. N. M. Schoffelmeer, "Cannabinoid Modulation of Executive Functions," European Journal of Pharmacology, Vol. 585, No. 2-3, 2008, pp. 458-463. doi:10.1016/j.ejphar.2008.02.099

[6] G. Riedel and S. N. Davies, "Cannabinoid Function in Learning, Memory and Plasticity,” In: R. G. Pertwee, Ed., Handbook of Experimental Pharmacology, Springer-Verlag, Berlin, 2005, pp. 445-478.

[7] R. G. Pertwee, "The Central Pharmacology of Psychotropic Cannabinoids," Pharmacological Therapeutics, Vol. 36, No. 2-3, 1988, pp. 189-261. doi:10.1016/0163-7258(88)90106-4

[8] J. S. Myer and L. F. Quenzer, "Psychopharmacology: Drugs, Brain, and Behavior," Sinauer, Sunderland, 2005.

[9] M. N. Hill and B. B. Gorzalka, "Enhancement of Anxiety-Like Responsiveness to the Cannabinoid CB1 Receptor Agonist HU-210 Following Chronic Stress," European Journal of Pharmacology, Vol. 499, No. 3, 2004, pp. 291-295. doi:10.1016/j.ejphar.2004.06.069

[10] H. V. Curran, C. Brignell, S. Fletcher, P. Middleton and J. Henry, "Cognitive and Subjective Low-Dose Effects of Acute Oral $\Delta 9$ Tetrahydrocannabionol (THC) in Infrequent Cannabis Users," Psychopharmacology, Vol. 164, No. 1, 2002, pp. 61-70. doi:0.1007/s00213-002-1169-0

[11] A. H. Lichtman, S. A. Varvel and B. R. Martin, "Endocannabinoids in Cognition and Dependence," Prostaglandins, Leukotrienes and Essential Fatty Acids, Vol. 66, No. 2-3, 2002, pp. 269-285. doi:10.1054/plef.2001.0351

[12] N. Solowij, "Cannabis and Cognitive Functioning," Cambridge University Press, Cambridge, 1998.

[13] H. R. Quinn, I. Matsumoto, P. D. Callaghan, L. E. Long, J. C. Arnold, N. Gunasekaran, M. R. Thompson, B. Dawson, P. E. Mallet, M. A. Kashem, H. Matsuda-Matsumoto, T. Iwazaki and I. S. McGregor, "Adolescent Rats Find Repeated Delta(9)-THC Less Aversive than Adult Rats but Display Greater Residual Cognitive Deficits and Changes in Hippocampal Protein Expression Following Exposure," Neuropsychopharmacology, Vol. 33,
No. 5, 2007, pp. 1113-1126. doi:10.1038/sj.npp.1301475

[14] M. Schneider and M. Koch, "Chronic Pubertal, but Not Adult Chronic Cannabinoid Treatment Impairs Sensorimotor Gating, Recognition Memory and the Performance in a Progressive Ratio Task in Adult Rats," Neuropsychopharmacology, Vol. 28, No. 10, 2003, pp. 17601769. doi: $10.1038 /$ sj.npp. 1300225

[15] M. O'Shea, M. E. Sing, I. S. McGregor and P. E. Mallet, "Chronic Cannabinoid Exposure Produces Lasting Memory Impairment and Increased Anxiety in Adolescent but Not Adult Rats," Journal of Psychopharmacology, Vol. 18 , No. 4, 2004, pp. 502-508. doi: $10.1177 / 0269881104047277$

[16] J. DuBach, "The Allure of 'Spice' Officials Claim Herb Mix Is a Dangerous Drug," Elko Daily Free Press, 2010. http://elkodaily.com/news/local/article_36fca382-cfc8-11 df-a3a9-001cc4c002e0.html\#ixzz1ZltDQzbJ

[17] I. Vardakou, C. Pistos and C. Spiliopoulou, "Spice Drugs as a New Trend: Mode of Action, Identification and Legislation," Toxicology Letters, Vol. 197, No. 3, 2010, pp. 157-162. doi:10.1016/i.toxlet.2010.06.002

[18] EMCDDA, "Thematic Papers: Understanding the 'Spice' Phenomenon," Lisbon, European Monitoring Centre for Drugs and Drug Addiction, 2009.

http://www.emcdda.europa.eu/html.cfm/index90917EN.h tml

[19] C. Mustata, M. Torrens, R. Pardo, C. Pérez, Psychonaut Web Mapping Group and M. Farré, "Spice Drugs: Cannabinoids as New Designer Drugs [Spanish]," Adicciones, Vol. 21, No. 3, 2009, pp. 181-186.

[20] Psychonaut Web Mapping Research Group, "Psyhonaut Web Mapping Project: Final Report," Institute of Psychiatry, King's College London, London, 2010.

[21] United States Drug Enforcement Administration, Office of Forensic Sciences, Microgram Bulletin, Vol. 44, No. 3, 2011.

http://www.justice.gov/dea/programs/forensicsci/microgr am/mg2011/mg0311.pdf

[22] R. Lindigkeit, A. Boehme, I. Eiserloh, M. Luebbecke, M. Wiggermann, L. Ernst and T. Beuerle, "Spice: A Never Ending Story?" Forensic Science International, Vol. 191, No. 1-3, 2009, pp. 58-63. doi:10.1016/j.forsciint.2009.06.008

[23] A. B. Schneir, J. Cullen and B. T. Ly, "'Spice' Girls: Synthetic Cannabinoid Intoxication," The Journal of Emergency Medicine, Vol. 40, No. 3, 2011, pp. 296-299. doi:10.1016/j.jemermed.2010.10.014

[24] U. S. Zimmermann, P. R. Winkelmann, M. Pilhatsch, J. A. Nees, R. Spanagel and K. Schulz, "Withdrawal Phenomena and Dependence Syndrome after the Consumption of 'Spice Gold'," Deutsches Ärzteblatt International, Vol. 106, No. 27, 2009, pp. 464-467. doi:10.3238/arztebl.2009.0464

[25] J. W. Huffman, "Cannabimimetic Indoles, Pyrroles, and Indenes: Structure-Activity Relationships and Receptor Interactions," In: P. H. Reggio, Ed., The Cannabinoid Receptors, Human Press, New York, 2009, pp. 49-94. doi:10.1007/978-1-59745-503-9 3 
[26] J. L. Wiley, D. R. Compton, D. Dai, J. A. H. Lainton, M. Phillips, J. W. Huffman and B. R. Martin, "Structure-Activity Relationships of Indole- and Pyrrole-Derived Cannabinoids," Journal of Pharmacology and Experimental Therapeutics, Vol. 285, No. 3, 1998, pp. 995-1004.

[27] AAPCC, "Fake Marijuana Spurs More than 2500 Calls to US Poison Centers This Year Alone," American Association of Poison Control Centers, Alexandria, 2010.

[28] EMCDDA, "Annual Report on the State of the Drugs Problem," European Monitoring Centre for Drugs and Drug Addiction, Lisbon, 2009.

[29] C. G. Lyketsos, E. Garrett, K. Y. Liang and J. C. Anthony, "Cannabis Use and Cognitive Decline in Persons under 65 Years of Age," American Journal of Epidemiology, Vol. 149, No. 9, 1999, pp. 794-800. doi:10.1093/oxfordjournals.aje.a009894

[30] P. Fried, B. Watkinson, D. James and R. Gray, "Current and Former Marijuana Use: Preliminary Findings of a Longitudinal Study of Effects on 10 in Young Adults," Journal of the Canadian Medical Association, Vol. 166, No. 7, 2002, pp. 887-891.

[31] A. Stiglick and H. Kalant, "Residual Effects of Chronic Cannabis Treatment on Behavior in Mature Rats," Psychopharmacology, Vol. 85, No. 4, 1985, pp. 436-439. doi:10.1007/BF00429660

[32] M. Schneider, E, Drews and M. Koch, "Behavioral Effects in Adult Rats of Chronic Prepubertal Treatment with the Cannabinoid Receptor Agonist WIN 55212-2," Behavioural Pharmacology, Vol. 16, No. 5-6, 2005, pp. 447-453. doi:10.1097/00008877-200509000-00018

[33] M. Schneider, E. Schömig and F. M. Leweke, "Acute and Chronic Cannabinoid Treatment Differentially Affects Recognition Memory and Social Behavior in Pubertal and Adult Rats," Addiction Biology, Vol. 13, No. 3-4, 2008, pp. 345-357. doi:10.1111/j.1369-1600.2008.00117.x

[34] D. Giuliani, F. Ferrari and A. Ottani, "The Cannabinoid Agonist HU 210 Modifies Rat Behavioural Responses to Novelty and Stress," Pharmacological Research, Vol. 41, No. 1, 2000, pp. 45-51. doi:10.1006/phrs.1999.0560

[35] M. Biscaia, S. Maŕin, B. Fernández, E. M. Marco, M. Rubio, C. Guaza, E. Ambrosio and M. P. Viveros, "Chronic Treatment with CP 55,940 during the PeriAdolescent Period Differentially Affects the Behavioural Responses of Male and Female Rats in Adulthood," Psychopharmacology, Vol. 170, No. 3, 2003, pp. 301-308. doi:10.1007/s00213-003-1550-7

[36] E. Tirelli, G. Laviola and W. Adriani, "Ontogenesis of Behavioral Sensitization and Conditioned Place Preference in Laboratory Rodents," Neuroscience and Biobehavioral Reviews, Vol. 27, No. 1-2, 2003, pp. 163-178. doi:10.1016/S0149-7634(03)00018-6

[37] L. P. Spear, "The Adolescent Brain and Age-Related Behavioral Manifestations," Neuroscience and Biobehavioral Reviews, Vol. 24, No. 4, 2000, pp. 417-463. doi:10.1016/S0149-7634(00)00014-2

[38] Psychonaut Web Mapping Research Group, "Spice Report," Institute of Psychiatry, King's College London, London, 2009.
[39] S. Every-Palmer, "Synthetic Cannabinoid JWH-018 and Psychosis: An Explorative Study," Drug and Alcohol Dependence, Vol. 117, No. 2-3, pp. 152-157. doi:10.1016/i.drugalcdep.2011.01.012

[40] Kikura-Hanajiri, N. Uchiyama and Y. Goda, "Survey of Current Trends in the Abuse of Psychotropic Substances and Plants in Japan," Legal Medicine, Vol. 13, No. 3, 2011, pp. 109-115. doi:10.1016/j.legalmed.2011.02.003

[41] L. W. Padgett, "Recent Developments in Cannabinoid Ligands," Life Sciences, Vol. 77, No. 14, 2005, pp. 17671798. doi:10.1016/j.1fs.2005.05.020

[42] M. M. Schmidt, A. Sharma, F. Schifano and C. Feinmann, "Legal Highs' on the Net: Evaluation of UKBased Websites, Products and Product Information," Forensic Science International, Vol. 206, No. 1-3, 2011, pp. 92-97. doi:10.1016/j.forsciint.2010.06.030

[43] T. Sobolevsky, I. Prasolow and G. Rodchenkow, "Detection of JWH-018 Metabolites in Smoking Mixture PostAdministration Urine," Forensic Science International, Vol. 200, No. 1-3, 2010, pp. 141-147. doi:10.1016/i.forsciint.2010.04.003

[44] Institute of Laboratory Animal Research, Commission on Life Sciences, "Guide for the Care and Use of Laboratory Animals," National Academies Press, Washington, 1996.

[45] R. P. Kesner, B. V. DiMattia and K. A. Crutcher, "Evidence for Neocortical Involvement in Reference Memory," Behavioral and Neural Biology, Vol. 47, No. 1, 1987, pp. 40-53. doi:10.1016/S0163-1047(87)90145-2

[46] A. Köfalvi, Ed., "Cannabinoids and the Brain," Springer, New York, 2008.

[47] R. G. Pertwee, "Pharmacological Actions of Cannabinoids," In: R. G. Pertwee, Ed., Cannabinoids: Handbook of Experimental Pharmacology (Vol. 168), SpringerVerlag, Heidelberg, 2005, pp. 1-52.

[48] A. Ameri, "The effects of Cannabinoids on the Brain," Progress in Neurobiology, Vol. 58, No. 4, 1999, pp. 315348. doi:10.1016/S0301-0082(98)00087-2

[49] C. S. Kearn and C. J. Hilliard, "Rat Microglial Cell Express the Peripheral-Type Cannabinoid Receptor (CB2) Which Is Negatively Coupled to Adenylyl Cyclase," International Cannabinoid Research Society, Vol. 1, Symposium on Cannabinoids, Burlington, 1997, p. 61.

[50] J. P. Gong, E. S. Onaivi, H. Ishiguro, Q. R. Liu, P. A. Tagliaferro, A. Brusco and G. R. Uhl, "Cannabinoid CB2 receptors: Immunohistochemical Localization in Rat Brain," Brain Research, Vol. 1071, No. 1, 2006, pp. 10-23. doi:10.1016/j.brainres.2005.11.035

[51] N. Hajos and T. F. Freund, "Pharmacological Separation of Cannabinoid Sensitive Receptors on Hippocampal Excitatory and Inhibitory Fibers," Neuropharmacology, Vol. 43, No. 4, 2002, pp. 503-510. doi:10.1016/S0028-3908(02)00157-0

[52] M. Herkenham, A. B. Lynn, M. D. Little, M. R. Johnson, L. S. Melvin, B. R. de Costa and K. C. Rice, "Cannabinoid Receptor Localization in Brain," Proceedings of $\mathrm{Na}$ tional Academy of Science USA, Vol. 87, No. 5, 1990, pp. 1932-1936.

[53] I. Katona, E. A. Rancz, L. Acsady, C. Ledent, K. Mackie, 
N. Hajos and T. F. Freund, "Distribution of CB1 Cannabinoid Receptors in the Amygdala and Their Role in the Control of GABAergic Transmission," The Journal of Neuroscience, Vol. 21, No. 23, 2001, pp. 9506-9518.

[54] S. J. Carlisle, F. Marciano-Cabral, A. Staab, C. Ludwick, and G. A. Cabral, "Differential Expression of the $\mathrm{CB}_{2}$ Cannabinoid Receptor by Rodent Macrophages and Macrophage-Like Cells in Relation to Cell Activation," International Immunopharmacology, Vol. 2, No. 1, 2002, pp. 69-82. doi:10.1016/S1567-5769(01)00147-3

[55] J. M. Sullivan, "Cellular and Molecular Mechanisms Underlying Learning and Memory Impairments Produced by Cannabinoids," Learning and Memory, Vol. 7, No. 3, 2000, pp. 132-139. doi:10.1101/1m.7.3.132

[56] S. N. Davies, R. G. Pertwee and G. Riedel, "Functions of Cannabinoid Receptors in the Hippocampus," Neuropharmacology, Vol. 42, No. 8, 2002, pp. 993-1007. doi:10.1016/S0028-3908(02)00060-6

[57] S. Da and R. N. Takahashi, "SR 141716A Prevents Delta 9-Tetrahydrocannabinol Induced Spatial Learning Deficit in a Morris-Type Water Maze in Mice," Progress in Neuropsychopharmacology and Biological Psychiatry, Vol. 26, No. 2, 2002, pp. 321-325. doi:10.1016/S0278-5846(01)00275-5

[58] L. Robinson, A. V. Goonawardena, R. G. Pertwee, R. E. Hampson and G. Riedel, "The Synthetic Cannabinoid HU210 Induces Spatial Memory Deficits and Suppresses Hippocampal Firing Rate in Rats," British Journal of Pharmacolology, Vol. 151, No. 5, 2007, pp. 688-700. doi:10.1038/sj.bjp.0707273

[59] S. A. Varvel, E. Anum, F. Niyuhire, L. E. Wise and A. H. Lichtman, "Delta(9)-THC-Induced Cognitive Deficits in Mice Are Reversed by the GABA(A) Antagonist Bicuculline," Psychopharmacology, Vol. 178, No. 2-3, 2005, pp. 317-327. doi:10.1007/s00213-004-1988-2

[60] S. A. Varvel, R. J. Hamm, B. R. Martin and A. H. Lichtman, "Differential Effects of Delta 9-THC on Spatial Reference and Working Memory in Mice," Psychopharmacology, Vol. 157, No. 2, 2001, pp. 142-150. doi: $10.1007 / \mathrm{s} 002130100780$

[61] K. Mishima, N. Egashira, N. Hirosawa, M. Fujii, Y. Matsumoto, K. Iwasaki and M. Fujiwara, "Characteristics of Learning and Memory Impairment Induced by Delta9Tetrahydrocannabinol in Rats," The Japanese Journal of Pharmacology, Vol. 87, No. 4, 2001, pp. 297-308. doi:10.1254/jijp.87.297

[62] E. M. Nakamura, E. A. da Silva, G. V. Concilio, D. A. Wilkinson and J. Masur, "Reversible Effects of Acute and Long-Term Administration of Delta-9-Tetrahydrocannabinol (THC) on Memory in the Rat," Drug and Alcohol Dependence, Vol. 28, No. 2, 1991, pp. 167-175. doi:10.1016/0376-8716(91)90072-7

[63] N. Wegener, S. Kuhnert, A. Thuns, R. Roese and M. Koch, "Effects of Acute Systemic and Intra-Cerebral Stimulation of Cannabinoid Receptors on Sensorimotor Gating, Locomotion and Spatial Memory in Rats," Psychopharmacology, Vol. 198, No. 3, 2008, pp. 375-385. doi:10.1007/s00213-008-1148-1

[64] L. E. Wise, A. J. Thorpe and A. H. Lichtman, "Hippo- campal CB(1) Receptors Mediate the Memory Impairing Effects of Delta(9)-Tetrahydrocannabinol," Neuropsychopharmacology, Vol. 34, No. 9, 2009, pp. 2072-2080. doi:10.1038/npp.2009.31

[65] T. T. Yim, N. S. Hong, M. Ejaredar, J. E. McKenna and R. J. McDonald, "Post-Training CB1 Cannabinoid Receptor Agonist Activation Disrupts Long-Term Consolidation of Spatial Memories in the Hippocampus," Neuroscience, Vol. 151, No. 4, 2008, pp. 929-936. doi:10.1016/j.neuroscience.2007.08.037

[66] S. K. Acheson, N. L. T. Moore, C. M. Kuhn, W. A. Wilson and H. S. Swartzwelder, "The Synthetic Cannabinoid WIN 55212-2 Differentially Modulates Thigmotaxis but Not Spatial Learning in Adolescent And Adult Animals," Neuroscience Letters, Vol. 487, No. 3, 2011, pp. 411-414. doi:10.1016/j.neulet.2010.10.067

[67] I. Akirav, "The Role of Cannabinoids in Modulating Emotional and Nonemotional Memory Processes in the Hippocampus," Frontiers in Behavioral Neuroscience, Vol. 5, 2011, p. 34.

http://www.frontiersin.org/behavioral_neuroscience/10.33 89/fnbeh.2011.00034/full

[68] D. L. Misner and J. M. Sullivan, "Mechanism of Cannabinoid Effects on Long Term Potentiation and Depression in Hippocampal CA1 Neurons," Journal of Neuroscience, Vol. 19, No. 16, 1999, pp. 6795-6805.

[69] M. Shen, T. M. Piser, V. S. Seybold and S. A. Thayer, "Cannabinoid Receptor Agonists Inhibit Glutamatergic Synaptic Transmission in Rat Hippocampal Cultures," The Journal of Neuroscience, Vol. 16, No. 14, 1996, pp. 4322-4334.

[70] A. V. Nowicky, T. J. Teyler and R. M. Vardaris, "The Modulation of Long Term Potentiation by Delta-9-Tetrahydrocannabinol in the Rat Hippocampus, in Vitro," Brain Research Bulletin, Vol. 19, No. 6, 1987, pp. 663672. doi:10.1016/0361-9230(87)90052-9

[71] D. R. Collins, R. G. Pertwee and S. N. Davies, "The Action of Synthetic Cannabinoids on the Induction of LongTerm Potentiation in the Rat Hippocampal Slice," European Journal of Pharmacology, Vol. 259, No. 3, 1994, pp. R7-R8. doi:10.1016/0014-2999(94)90666-1

[72] D. R. Collins, R. G. Pertwee and S. N. Davies, "Prevention by the Cannabinoid Antagonist, SR141716A, of Cannabinoid-Mediated Blockade of Long-Term Potentiation in the Rat Hippocampal Slice," British Journal of Pharmacology, Vol. 115, No. 6, 1995, pp. 869-870.

[73] J. P. Terranova, J. C. Michaud, G. Le Fur and P. Soubrié, "Inhibition of Long-Term Potentiation in Rat Hippocampal Slices by Anandamide and WIN55212-2: Reversal by SR141716 A, a Selective Antagonist of CB1 Cannabinoid Receptors," Naunyn-Schmiedeberg's Archives of Pharmacology, Vol. 352, No. 5, 1995, pp. 576-579. doi:10.1007/BF00169393

[74] W. Adriani and G. Laviola, "Windows of Vulnerability to Psychopathology and Therapeutic Strategy in the Adolescent Rodent Model," Behavioural Pharmacology, Vol. 15, No. 5-6, 2004, pp. 341-352. doi:10.1097/00008877-200409000-00005

[75] M. R. Domenici, S. C. Azad, G. Marsicano, A. Schierloh, 
C. T. Wotjak, H. U. Dodt, W. Zieglgansberger, B. Lutz and G. Rammes, "Cannabinoid Receptor Type 1 Located on Presynaptic Terminals of Principal Neurons in the Forebrain Controls Glutamatergic Synaptic Transmission," The Journal of Neuroscience, Vol. 26, No. 21, 2006, pp. 5794-5799. doi:10.1523/jneurosci.0372-06.2006

[76] M. Haring, G. Marsicano, B. Lutz and K. Monory, "Identification of the Cannabinoid Receptor Type 1 in Serotonergic Cells of Raphe Nuclei in Mice," Neuroscience, Vol. 146, No. 3, 2007, pp. 1212-1219. doi:10.1016/j.neuroscience.2007.02.021

[77] A. F. Hoffman and C. R. Lupica, "Mechanisms of Can- nabinoid Inhibition of GABA(A) Synaptic Transmission in the Hippocampus," The Journal of Neuroscience, Vol. 20, No. 7, 2000, pp. 2470-2479.

[78] K. A. Seely, P. L. Prather, L. P. James and J. H. Moran, "Marijuana-Based Drugs: Innovative Therapeutics or Designer Drugs of Abuse?" Molecular Interventions, Vol. 11, No. 1, 2011, pp. 36-51. doi:10.1124/mi.11.1.6

[79] V. C. Oropeza, K. Mackie and E. J. Van Bockstaele, "Cannabinoid Receptors Are Localized to Noradrenergic Axon Terminals in the Rat Frontal Cortex," Brain Research, Vol. 1127, No. 1, pp. 36-44. doi:10.1016/j.brainres.2006.09.110 